\title{
Elaboração de cartas geotécnicas aplicadas a solos colapsíveis em áreas urbanas utilizando o método do detalhamento progressivo
}

\author{
Elaboration of geotechnical charts applied to collapsible soils \\ in urban areas using the Progressive Detailing Method \\ Paulo Edison Martins da Silveira ${ }^{1}$ (D), Fábio Augusto Gomes Vieira Reis ${ }^{2}$ (1) \\ ${ }^{1}$ Escola de Engenharia de Piracicaba da Fundação Municipal de Ensino de Piracicaba - EEP/FUMEP. Travessa Prates, 200, \\ Centro, CEP 13395-035, Rio das Pedras, SP, BR (martinsdasilveira@yahoo.com.br) \\ 2Universidade Estadual Paulista “Júlio de Mesquita Filho" - UNESP, Instituto de Geociências e Ciências Exatas - IGCE, \\ Rio Claro, SP, BR (fabio.reis@unesp.br)
}

Recebido em 31 de agosto de 2020; aceito em 7 de abril de 2021.

\begin{abstract}
Resumo
Muitos trabalhos tratam da colapsividade de solos, porém poucos são voltados para o planejamento urbano. Este trabalho apresenta procedimentos para elaboração de cartas geotécnicas aplicadas a solos colapsíveis em áreas urbanas, discutindo a influência da escala de trabalho, dos procedimentos de mapeamento geotécnico e dos ensaios laboratoriais para a avaliação do fenômeno. O trabalho buscou critérios de elaboração de cartas geotécnicas aplicados a solos colapsíveis nessas áreas, com base no método do detalhamento progressivo, focando nos principais condicionantes à ocorrência do processo e nos ensaios geotécnicos mais adequados em cada etapa de estudo. O trabalho apresenta os resultados obtidos nas duas etapas do referido método, a geral (1:50.000) e a de semidetalhe (1:25.000). Na primeira etapa, foram executados os seguintes procedimentos: análise de documentações cartográficas temáticas e compilação bibliográfica; fotointerpretação; levantamento de campo; realização de ensaios laboratoriais; análise de perfis de sondagens geotécnicas; elaboração de carta geotécnica (1:50.000) com geração de unidades geológico-geotécnicas pela análise multitemática com cruzamento de dados de declividade, hipsométricos, geológicos, pedológicos, geotécnicos e laboratoriais; e, finalizando, esses resultados foram integrados para definir zonas suscetíveis à ocorrência desses solos e a escolha da área-alvo para os estudos da etapa de semidetalhe. Na segunda etapa, foram executadas as seguintes atividades: levantamento complementar dessa área, ensaios edométricos para confirmação de ocorrência ao fenômeno e elaboração de carta geotécnica (1:25.000). Pelos resultados obtidos, conclui-se que a metodologia do detalhamento progressivo, com suas diferentes escalas de trabalho, objetivos e procedimentos, apresenta-se como uma ferramenta importante na elaboração de cartas de suscetibilidade ao fenômeno da colapsividade de solos em áreas urbanas, com vantagem de otimizar recursos financeiros, pessoais e tempo disponíveis.
\end{abstract}

Palavras-chave: Colapsividade de solos; Mapeamento geotécnico; Colapsividade em áreas urbanas.

\begin{abstract}
Many works deal with the collapse of soils; however, few are focused on urban planning. The present paper presents procedures for the elaboration of geotechnical charts applied to collapsible soils in urban areas, discussing the influence of the work scale, geotechnical mapping procedures, and laboratory tests for the assessment of the phenomenon. The work sought criteria for the elaboration of geotechnical maps applied to collapsible soils in these areas, based on the method of progressive detailing, focusing on the main constraints to the occurrence of the process and the most appropriate geotechnical tests in each study stage. Herein, the results obtained for two stages of the referred method are presented, the general $(1: 50,000)$ and the semi-detail $(1: 25,000)$. In the first, the following procedures were performed: analysis of thematic cartographic documentation and bibliographic compilation; photointerpretation; field survey; conducting laboratory tests; analysis of geotechnical survey profiles; elaboration of a geotechnical chart $(1: 50,000)$ with the generation of geological-geotechnical units by multithematic analysis with crossing of declivity, hypsometric, geological, pedological, geotechnical, and laboratory data; and finally, these results were integrated to define susceptible zones the occurrence of these soils and the choice of the target area for the studies of the semidetail stage. In this
\end{abstract}


stage, the following activities were carried out: complementary survey of this area, edometric tests to confirm the occurrence of the phenomenon, and the elaboration of a geotechnical chart $(1: 25,000)$. Based on the results obtained, the conclusion is that the progressive detailing methodology, with its different work scales, objectives and procedures, presents itself as an important tool in the elaboration of susceptibility charts to the phenomenon of soil collapse in urban areas, with the advantage of optimize financial, personal, and time resources.

Keywords: Soil collapsibility; Geotechnical mapping; Collapse in urban areas.

\section{INTRODUÇÃO}

Em suas necessidades de energia, transporte, alimentação, moradia, segurança física, saúde, comunicação etc., em função do aumento populacional urbano, o homem busca e modifica outros espaços naturais, inclusive espaços urbanos. Caso algum desses empreendimentos desconsidere as características dos materiais e os processos geológicos naturais, desde a fase de projeto até a implantação e a operação deles, com que vão interferir e interagir, certamente a natureza responde na forma de acidentes localizados ou problemas regionais (Santos, 2017).

Entre essas características, apresenta-se o fenômeno da colapsividade de solo, que pode ser entendido como aquele que, com o teor de umidade natural, ao ser carregado, comprime-se suavemente e sem variação expressiva de volume, pois resiste ao esforço de compressão entre os grãos. Todavia, esse solo, ao sofrer aumento de umidade, atingindo teor crítico, tem seus vínculos de resistência enfraquecidos e a estrutura entra em colapso (Jennings e Knight, 1957). Já Pinto (2002) define solos colapsíveis como aqueles solos não saturados que apresentam considerável e rápida compressão quando submetidos a aumento de umidade sem que varie a tensão total a que estejam submetidos; o fenômeno da colapsividade decorre da destruição dos meniscos capilares, responsáveis pela tensão de sucção, ou de um amolecimento do cimento natural que mantinha as partículas e as agregações de partículas unidas, e está fisicamente associado à perda de resistência dos solos não saturados. A colapsividade dos solos geralmente é estudada por meio de ensaios de compressão edométrica com inundação. Durante o carregamento axial, a inundação do solo diminui a pressão de sucção ou amolece o cimento natural, provocando o colapso e as microrrupturas, que se manifestam só pelo recalque em virtude de o solo estar contido no anel do ensaio edométrico.

Há inúmeros problemas relacionados ao uso e à ocupação de terrenos em áreas de solos colapsíveis (por exemplo, os recalques de terrenos e de fundação), e como consequências, pode-se citar a danificação de edificações, obras de infraestrutura e leitos viários em áreas urbanas e rurais. Muitos projetos de engenharia desconsideram os efeitos decorrentes causados pelo fenômeno da colapsividade.
A ocorrência de solos colapsíveis é mais frequente em regiões de clima quente. Contudo, há registro da existência desses solos em outras partes do mundo, associados a climas diversos. Como exemplos de ocorrência de solos colapsíveis, pode-se citar os loess da Romênia (Popescu, 1986); os solos colapsíveis na Jordânia (Basma e Tuncer, 1992); os solos eólicos do Egito (Gaaver, 2012; Ayadat e Hanna, 2013); as areias colapsíveis na Sicília (Ercoli et al., 2015); os solos loessicos na Moldávia (Olyansky et al., 2016); e os solos colapsíveis da região de Albuquerque, no Estado do Novo México, Estados Unidos (Lommler e Bandini, 2015). Os loess, muito susceptíveis aos fenômenos colapsíveis, ocupam 17\% dos Estados Unidos, 17\% da Europa, partes da China e estão presentes na Nova Zelândia e nas regiões planas da Argentina e do Uruguai (Clemence e Finbarr, 1981). No Brasil, segundo Rodrigues e Lollo (2008), os solos colapsíveis são identificados em todas as regiões do país. Nesse sentido, verifica-se que os climas quentes e áridos, embora predominantes, não representam condições essenciais para o desenvolvimento de solos colapsíveis. Solos com potencial colapsível recobrem parte considerável do estado de São Paulo, principalmente em áreas aplainadas do Planalto Ocidental, com substratos arenosos, e da depressão periférica de substratos silto-argilosos (Nakazawa et al., 1995). Vários autores citam a ocorrência de solos colapsíveis em território paulista, como em São Carlos (Teixeira, 1993; Souza Neto, 2004), Pereira Barreto (Pinto, 2002) e Rio Claro (Zaine, 2000). As ocorrências desses solos não são pontuais, e sim de ocorrência generalizada, tanto em relação à abundância quanto à genética de formação deles. Daí a necessidade de se buscar metodologias práticas para a identificação desses solos, quando de sua utilização para o planejamento e o desenvolvimento urbano dos municípios, e escolher um método de mapeamento e uma escala adequados quando se propõe a apresentar uma carta de suscetibilidade ao fenômeno da colapsividade de solos.

No âmbito da geologia urbana, o mapeamento geotécnico é uma importante ferramenta que fornece parâmetros para estabelecer mapas de adequação dos terrenos para fins construtivos e para uma expansão urbana de forma segura (El May et al., 2010). Em trabalho sobre mapeamento geotécnico no planejamento de expansão urbana de Túnis, 
capital da Tunísia, os autores citam que uma metodologia de mapeamento a ser seguida deve abordar a escolha de uma escala apropriada, a seleção de um método de mapeamento de geologia urbana e a compilação de mapas na produção final para o planejamento urbano, em que se deve contemplar a natureza dos materiais geológicos superficiais, a topografia, as propriedades e as características geotécnicas dos materiais e os dados obtidos por sondagens. A escala utilizada no trabalho foi de 1:25.000 e, segundo os autores, expressa os parâmetros e permite uma avaliação bem-sucedida para efeito construtivo. Não obstante, a escolha da escala de mapeamento geotécnico depende de alguns critérios: detalhamento do mapa e da área, complexidade, mapas utilizados (geológicos, pedológicos, folhas topográficas) e fotos aéreas (Price, 1981).

Zuquette (1993) propõe o termo "carta geotécnica" para representar os resultados da interpretação dos atributos do meio físico, mais utilizados nos estudos de expansão urbana, em escala maior que 1:100.000 e menor que 1:5.000.

Cerri et al. (1996) apresentam uma metodologia de mapeamento geológico-geotécnico denominada "método do detalhamento progressivo". Esse método consiste em três etapas de desenvolvimento dos trabalhos: a primeira etapa (etapa geral) apresenta o mapeamento em escala 1:50.000 ou 1:25.000, a partir da integração de dados de levantamentos realizados em diferentes escalas e com eventuais complementações; a segunda etapa (etapa intermediária) mostra um mapeamento em escala 1:25.000 ou 1:10.000 em áreas selecionadas na primeira etapa; e a terceira etapa (etapa de detalhe) refere-se a um mapeamento em escala 1:5.000, em locais com concentração de informações correlacionadas a tópicos específicos.

$\mathrm{Na}$ análise da eficácia do método de detalhamento progressivo, Zaine (2000), em trabalho de mapeamento geológico-geotécnico por meio desse método, em ensaio de aplicação na área urbana do município de Rio Claro, São Paulo, conclui que esse método mostra boa compatibilidade entre o volume de dados, os tipos de informações, o tamanho da área e a escala de trabalho nas três etapas. Segundo esse autor, o estudo relacionado às etapas geral e de semidetalhe permite a indicação do comportamento colapsível do solo e outros aspectos geotécnicos, por meio da correlação de atributos fisiográficos e geotécnicos. Dessa forma, o método de detalhamento progressivo é indicado para avaliações geotécnicas em áreas urbanas e obras que necessitem priorizar locais para aplicação de recursos detalhados em seu mapeamento, inclusive na identificação aprofundada da suscetibilidade a determinados processos de dinâmica superficial, entre eles a colapsividade.

A cartografia geotécnica e os ensaios laboratoriais de caracterização e edométricos são instrumentos adequados para a avaliação de solos colapsíveis. Considerando-se que os procedimentos adotados na etapa geral do detalhamento progressivo são bastante simples, por meio da correlação de atributos fisiográficos e geotécnicos obtidos em ensaios laboratoriais simples de caracterização, porém suficientes para a avaliação da suscetibilidade ao fenômeno da colapsividade do solo; e considerando-se que ensaios mais complexos, como os edométricos, são necessários somente na etapa intermediária para a confirmação da presumível colapsividade, a elaboração de uma carta geotécnica dentro do padrão de detalhamento progressivo atende às necessidades metodológicas para a avaliação da suscetibilidade ao fenômeno em áreas urbanas.

Vários autores apresentam critérios investigativos para a identificação de solos colapsíveis tanto em nível global quanto em situações brasileiras. Evidentemente, alguns critérios se apresentam mais exequíveis que outros em se tratando de avaliação preliminar do fenômeno da colapsividade, o que os tornam mais interessantes na primeira etapa do detalhamento progressivo, face a simplicidade operacional. Assim, os critérios de Priklonskij (1952), Miheev (1962 apud Gibbs e Bara, 1967), Feda (1966), Andrei e Athanasiu (1979), Zuquette (1993), Ayadat e Hanna (2012), Vilar e Rodrigues (2015) e Lommler e Bandini (2015) foram os adotados para a primeira etapa (etapa geral) do trabalho, estabelecida pela metodologia do detalhamento progressivo. Basicamente, esses critérios são contemplados com ensaios de caracterização física, granulométrica, de índices de consistência e compactação. Já os critérios investigativos, que se baseiam em ensaios edométricos, embora apresentem resultados mais confiáveis, no que se refere a solos colapsíveis, em razão das dificuldades impostas por eles, foram considerados mais oportunos no desenvolvimento da segunda etapa (etapa intermediária) neste trabalho, de acordo com o preconizado na metodologia do detalhamento progressivo.

Nesse sentido, o presente artigo teve como objetivo propor procedimentos para a elaboração de cartas geotécnicas aplicadas a solos colapsíveis em áreas urbanas, considerando os fundamentos do método do detalhamento progressivo nas etapas regional e de semidetalhe.

Esses procedimentos devem ser entendidos como um processo que envolve levantamento de dados de campo, otimizando a execução de ensaios laboratoriais para a caracterização do potencial colapsível dos solos. A proposta deste artigo tem aplicação no planejamento urbano, assim como nas fases preliminares de obras civis, como pontes, viadutos, edificações, sistemas de distribuição de água e coleta de esgoto, entre outras. Já nas fases de projetos executivos desses tipos de obras, haveria a necessidade de aplicação da terceira etapa do método de detalhamento progressivo (etapa de detalhe), com a execução de ensaios mais específicos, além dos edométricos, como os ensaios de placa, e uso de expanso-colapsômetro e sondagens geotécnicas. 
Neste trabalho, a área de estudo escolhida foi a área urbana de Piracicaba, São Paulo, cidade de porte médio que, como outras do Brasil, apresenta acentuada expansão urbana, que vem avançando sobre terrenos ainda pouco estudados e com algum potencial ao colapso de solos.

\section{MÉTODOS E ETAPAS DA PESQUISA}

Para o desenvolvimento deste trabalho, foram realizadas as duas primeiras etapas propostas pela metodologia do detalhamento progressivo (Cerri et al., 1996), ou seja, as etapas geral e intermediária.

\section{Etapa geral do detalhamento progressivo}

A etapa geral foi iniciada por uma revisão bibliográfica para subsidiar uma fundamentação teórica do estado de arte dos estudos dos fenômenos da colapsividade, especialmente relacionada a técnicas e métodos aplicados à avaliação da colapsividade de solos. Além disso, foram realizadas a organização e a compilação da base cartográfica e de mapas temáticos a serem usados no mapeamento.

Especificamente para o mapeamento da primeira etapa do detalhamento progressivo, foram realizadas as seguintes atividades:

- Compartimentação para definição preliminar das unidades geológico-geotécnicas, obtidas pela análise integrada de imagens aéreas da área de estudo, mapas temáticos (declividade, hipsometria, geologia e pedologia) e informações sistematizadas de sondagens geotécnicas executadas na área em questão;

- Levantamento de campo com 108 pontos de análise, vários deles com coleta de amostras para caracterização, principalmente, dos perfis de alteração de solo da área de estudo;

- Execução de ensaios laboratoriais para caracterização e estudo de compactação do solo;

- Classificação granulométrica e textural baseada nos resultados dos ensaios laboratoriais;

- Realização da classificação unificada e da classificação rodoviária. Embora essas classificações não sejam conclusivas para efeito de avaliação da suscetibilidade dos solos ao colapso, elas dão uma noção de comportamento colapsível em nível regional;

- Determinação do grau de suscetibilidade ao fenômeno da colapsividade, de acordo com critérios propostos por Priklonskij (1952); de Miheev (1962 apud Gibbs e Bara, 1967); de Feda (1966); de Andrei e Athanasiu (1979); de Zuquette (1993); de Ayadat e Hanna (2012); de Vilar e Rodrigues (2015); e de Lommler e Bandini (2015). Basicamente, esses critérios são contemplados com ensaios de caracterização física, determinação granulométrica, determinação dos índices de consistência e estudo de compactação. Para efeito de avaliação de suscetibilidade ao fenômeno da colapsividade nessa primeira etapa, esses critérios foram adotados pela sua simplicidade e rapidez de execução. Em seguida, foram propostos pesos $0,1,2 \mathrm{e} 4$ para cada um desses critérios adotados, em que: peso $0=$ não atendimento das condições apresentadas; peso 1 = indefinição ou atendimento parcial das condições propostas; peso 2 = atendimento das condições apresentadas; e peso 4 = atendimento das condições do critério de Lommler e Bandini (2015), por considerarem mais parâmetros que outros autores, conforme apresentado na Tabela 1. Dessa forma, pode-se classificar os graus de suscetibilidade ao fenômeno da colapsividade de solos, baseados em intervalos de pesos que correspondem à somatória dos valores nos seguintes termos: muito pouco suscetível ( 0 a 4$)$, pouco suscetível (5 a 8), suscetível (9 a 12) e altamente suscetível (13 a 18);

- Integralização da compartimentação preliminar (declividade, hipsometria, geologia, pedologia e informações obtidas nas sondagens geotécnicas) com a análise dos aspectos geotécnicos observados nos ensaios laboratoriais, enfatizando a interpretação de unidades com maior suscetibilidade ao fenômeno da colapsividade, gerando assim as unidades geológico-geotécnicas finais. A integralização da análise dos resultados laboratoriais (caracterização, granulometria e compactação), da análise da determinação do grau de suscetibilidade ao fenômeno do colapso do solo e das informações obtidas nas sondagens geotécnicas (aspectos texturais, gênese, resistência à penetração do solo, aspectos litológicos e pedológicos, profundidade do nível d'água), juntamente com as informações morfométricas (declividade e hipsometria), definiu as unidades geológico-geotécnicas aplicadas a solos colapsíveis, levando em consideração as diferenças comportamentais dos solos, principalmente em relação à potencialidade presumível da colapsividade. As informações hipsométricas foram consideradas, haja vista que os solos que demonstraram maior suscetibilidade são aqueles pertinentes às coberturas correlatas à Formação Rio Claro e sabidamente localizados em cotas próximas de $600 \mathrm{~m}$. Dessa forma, as unidades geológico-geotécnicas foram geradas a partir das informações fisiográficas associadas às características geológicas, pedológicas, de declividade e de hipsometria, com a utilização de produtos gerados nos programas QuantumGIS e o ArcGis (compartimentação geotécnica preliminar), da integração com os dados e da análise dos resultados laboratoriais, que permitiram a avaliação do potencial colapsível (unidades geológico-geotécnicas); 
Tabela 1. Critérios para avaliação da suscetibilidade ao fenômeno da colapsividade.

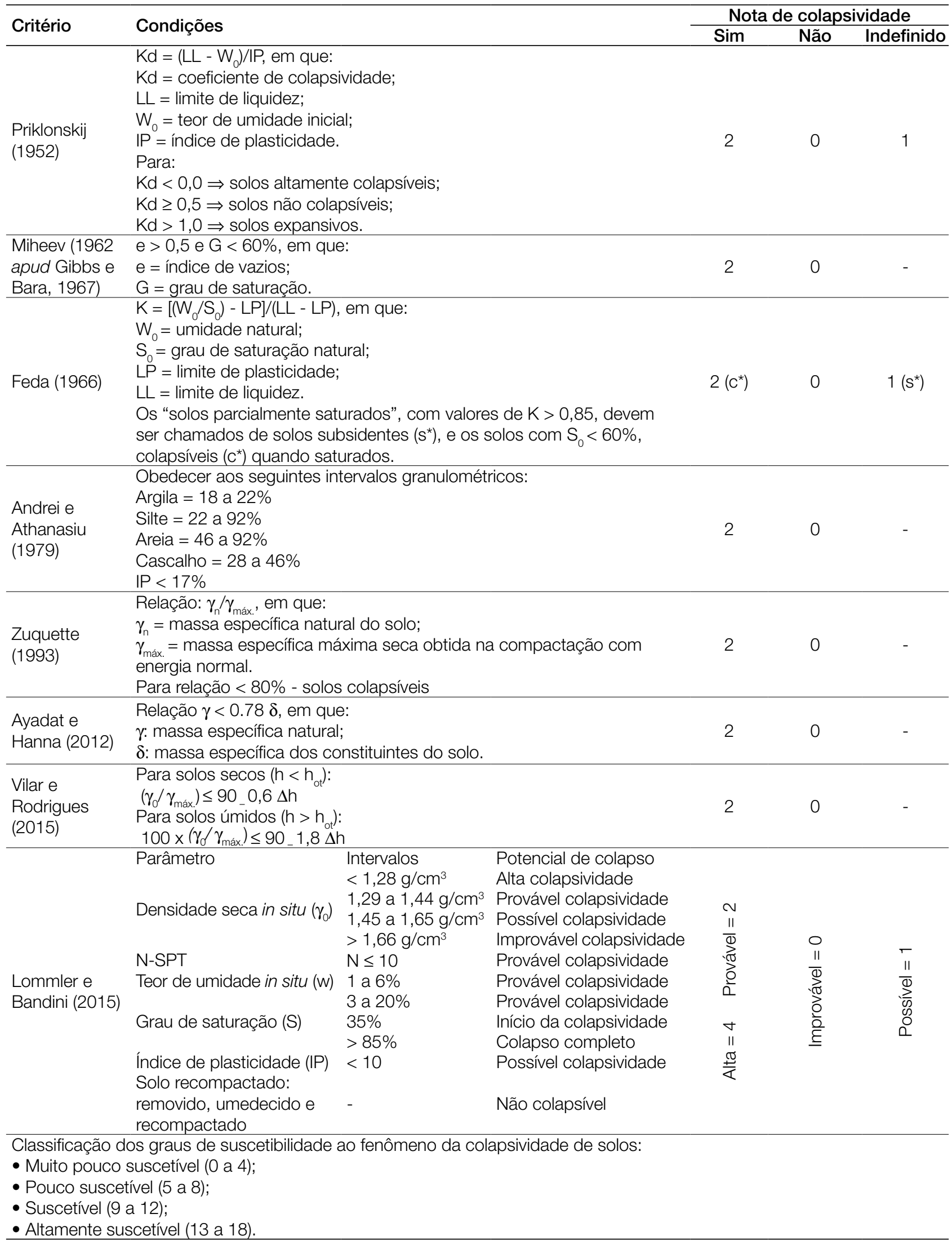


- Elaboração de carta geológico-geotécnica, em escala 1:50.000, aplicada à ocorrência do fenômeno da colapsividade de solos da área urbana do município de Piracicaba, contemplando as unidades geológico-geotécnicas e considerando as diferenças comportamentais dos solos, principalmente em relação à potencialidade presumível da colapsividade.

Os procedimentos metodológicos dessa primeira etapa estão sintetizados no fluxograma da Figura 1. A partir desses procedimentos, foi possível definir uma área-alvo para a aplicação do detalhamento progressivo em sua etapa intermediária, contemplando uma área de solos com alto grau de suscetibilidade aos fenômenos de colapsividade.

\section{Etapa intermediária do detalhamento progressivo}

Após a escolha da área-alvo no contexto das unidades geológico-geotécnicas com maiores graus de suscetibilidade ao fenômeno da colapsividade de solos, foram realizados os seguintes procedimentos metodológicos:

- Levantamento complementar de campo para análise e coleta de amostras na área-alvo;

- Coleta de amostras deformadas e indeformadas em pontos complementares com a finalidade de detalhamento maior na escala 1:25.000;

- Ensaios laboratoriais de caracterização física, granulométrica, de consistência e compactação nas amostras complementares;

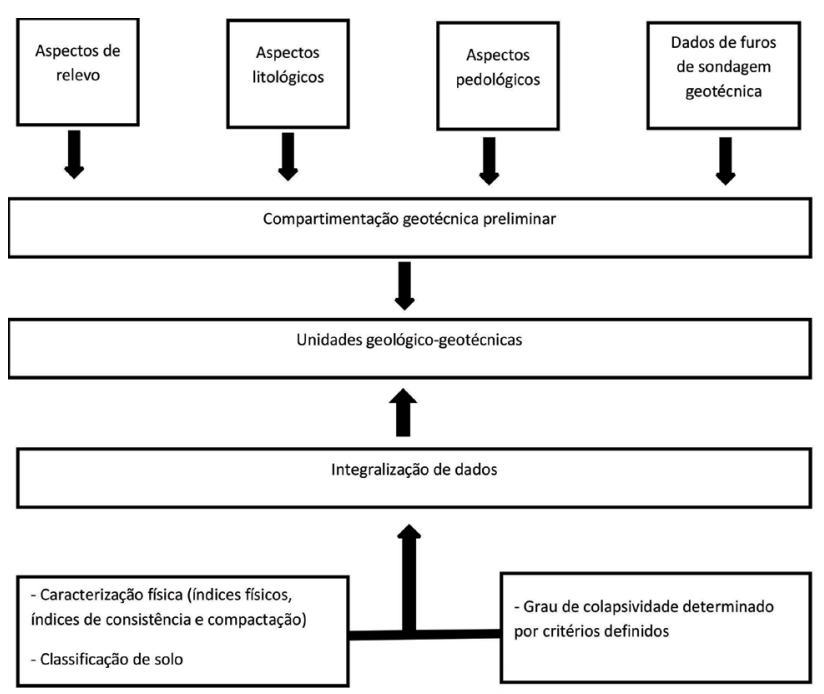

Figura 1. Fluxograma para a geração de unidades geológico-geotécnicas da carta geológico-geotécnica aplicada a solos colapsíveis na etapa geral.
- Determinação do grau de suscetibilidade ao colapso das amostras ensaiadas, considerando os mesmos critérios da etapa geral;

- Execução de ensaios edométricos, que nortearam a constatação da presumível colapsividade dos solos da área-alvo. A execução dos ensaios de adensamento seguiu a metodologia D 2435-96 Standard Method for OneDimensional Consolidation Properties of Soils (ASTM, 1996), e o potencial de colapsividade desses solos pode ser avaliado pelo método da norma técnica D 5333 Standard Test Method for Measurement of Collapse Potential of Soils (ASTM, 2003). Esse método contempla a determinação do potencial de colapso de uma amostra de solo não saturada quando passa para uma situação de saturação ao ser submetida a um esforço vertical axial unidimensional. O método mostra que solos colapsíveis sofrem uma diminuição de altura quando confinados e seguidos de saturação sob uma tensão vertical aplicada de forma constante. $O$ índice de colapso - Ic (porcentual de potencial relativo ao colapso determinado a $200 \mathrm{kPa}$ ) é calculado pela Equação 1 .

$\mathrm{Ic}=\left[\left(\Delta_{\mathrm{e}} / 1+\mathrm{e}_{0}\right)\right] 100(\%)$

Em que:

$\Delta_{\mathrm{e}}=$ variação do índice de vazios resultante da saturação; $\mathrm{e}_{0}=$ índice de vazio inicial.

O grau de colapsividade é determinado a partir dos resultados dos índices de colapso, conforme demonstrado na Tabela 2:

- Realização da classificação unificada e da classificação rodoviária;

- Elaboração de carta geotécnica aplicada a solos colapsíveis em escala 1:25.000: as unidades geológico-geotécnicas geradas nessa etapa intermediária focaram na suscetibilidade ao fenômeno da colapsividade de solos, de acordo com os atributos de cada unidade. Para tanto, fez-se necessário a interpretação de imagens aéreas; a elaboração de mapas de declividade e hipsométricos, com a utilização de base topográfica mundial apresentada pelo Satélite Alos-2; e a integração com a análise

Tabela 2. Classificação dos índices de colapso.

\begin{tabular}{lc}
\hline Grau de colapsividade & Índice de colapso (\%) \\
\hline Nulo & 0 \\
Leve & 0,1 a 2 \\
Moderado & 2,1 a 6 \\
Moderadamente severo & 6,1 a 10 \\
Severo & $>10$ \\
\hline
\end{tabular}

Fonte: D 5353 (ASTM, 2003). 
Tabela 3. Descrições dos aspectos morfométricos, pedológicos e litológicos das unidades geológico-geotécnicas.

\begin{tabular}{|c|c|c|c|c|c|}
\hline Unidade & Declividade (\%) & $\begin{array}{c}\text { Classe } \\
\text { hipsométrica } \\
\end{array}$ & $\begin{array}{l}\text { Associação } \\
\text { pedológica }\end{array}$ & Litologias & Unidades litológicas \\
\hline 1 & $0-8$ & Geral & $\begin{array}{c}\text { Latossolo vermelho (LV) } \\
+ \text { nitossolo vermelho } \\
\text { (NV) }\end{array}$ & Folhelhos/siltitos/argilitos & $\begin{array}{l}\text { Fm. Tatuí + Fm. Irati + } \\
\text { Fm. Corumbataí }+{ }^{*} \text { Fm. } \\
\text { Rio Claro }\end{array}$ \\
\hline$\|$ & $0-20$ & Geral & $\begin{array}{l}\text { Latossolo vermelho (LV) } \\
+ \text { nitossolo vermelho } \\
\text { (NV) }\end{array}$ & Diabásio & Fm. Serra Geral \\
\hline III & $0-8$ & $580-670$ & $\begin{array}{c}\text { Latossolo ou argissolo } \\
\text { vermelho-amarelo de } \\
\text { textura média (LVA + } \\
\text { PVA) }\end{array}$ & $\begin{array}{c}\text { Arenitos/coberturas } \\
\text { cenozoicas }\end{array}$ & $\begin{array}{l}\text { Fm. Pirambóia }+{ }^{*} \text { Fm. } \\
\text { Rio Claro }\end{array}$ \\
\hline IV & $0-8$ & Geral & $\begin{array}{c}\text { Cambissolo háplico }(\mathrm{CX}) \\
\text { + neossolo litólico }(\mathrm{RL})+ \\
\text { neossolo regolítico }(\mathrm{RR})\end{array}$ & Folhelhos/siltitos/argilitos & $\begin{array}{l}\text { Fm. Tatuí + Fm. Irati + } \\
\text { Fm. Corumbataí }\end{array}$ \\
\hline V & $0-20$ & Geral & $\begin{array}{c}\text { Argissolos em geral (PV/ } \\
\text { PVA) + nitossolo háplico } \\
(\mathrm{NX})\end{array}$ & Folhelhos/siltitos/argilitos & $\begin{array}{l}\text { Fm. Tatuí + Fm. Irati + } \\
\text { Fm. Corumbataí }\end{array}$ \\
\hline $\mathrm{Vl}$ & $0-8$ & $457-550$ & $\begin{array}{c}\text { Gleissolos + neossolo } \\
\text { flúvico }\end{array}$ & Geral & Geral \\
\hline VII & $3-20$ & Geral & $\begin{array}{l}\text { Cambissolo háplico }(\mathrm{CX}) \\
\text { + neossolo litólico }(\mathrm{RL})+ \\
\text { neossolo regolítico }(\mathrm{RR})\end{array}$ & Diabásio & Fm. Serra Geral \\
\hline VIII & $>8$ & Geral & $\begin{array}{l}\text { Cambissolo háplico }(\mathrm{CX}) \\
+ \text { Neossolo litólico }(\mathrm{RL})+ \\
\text { neossolo regolítico }(\mathrm{RR})\end{array}$ & Geral & Geral \\
\hline
\end{tabular}

*Fm. Rio Claro: cobertura correlata à Formação Rio Claro.

dos resultados laboratoriais de caracterização, compactação e edométricos, que permitiram a geração das unidades geológico-geotécnicas de acordo com suas classes de suscetibilidade ao colapso.

\section{RESULTADOS}

$\mathrm{Na}$ área de estudo deste trabalho, foram identificadas oito unidades geológico-geotécnicas na etapa de mapeamento geral na escala 1:50.000. A Tabela 3 descreve os atributos morfométricos, pedológicos e litológicos dessas unidades, enquanto a Tabela 4 detalha as características geotécnicas. Já a Figura 2 apresenta a carta geotécnica aplicada a solos colapsíveis da etapa geral do mapeamento da área de estudo.

Pela análise dos resultados, verificam-se as áreas da unidade geológico-geotécnica III, associada às coberturas cenozoicas correlatas à Formação Rio Claro e ao latossolo vermelho-amarelo (LVA) - ou, esporadicamente, ao argissolo vermelho-amarelo (PVA) - , com textura média. São as áreas mais suscetíveis ao fenômeno da colapsividade, apresentando graus de suscetibilidade ao colapso variando de 10 a 14 (suscetível a altamente suscetível). De acordo com o sistema unificado de classificação do solo, essa unidade apresentou amostras classificadas como CL, SM e SC; e de acordo com o sistema rodoviário, como A6, A4 e A2-4.

Essas coberturas cenozoicas estão situadas em altimetrias entre 570 e $580 \mathrm{~m}$, podendo atingir até $20 \mathrm{~m}$ de espessura. Via de regra, as sondagens executadas nesses materiais não encontraram o nível freático antes da mudança de material. Os valores de resistência à penetração do solo (N-SPT) são relativamente baixos ( 2 a 8 ) nos primeiros $8 \mathrm{~m}$ das perfurações e vão aumentando gradativamente para valores próximos de 20 até o contato com camadas subjacentes. Foi possível estabelecer uma correlação desses materiais geológicos descritos pelas sondagens geotécnicas com aqueles observados em campo nos trabalhos de mapeamento.

Como características comportamentais das unidades geológico-geotécnicas que contemplam solos que apresentam alto grau de susceptibilidade ao fenômeno da colapsividade, pode-se citar o alto poder de absorção de água e a alta drenabilidade, provocando baixos escoamentos superficiais, favorecendo assim a infiltração de água para horizontes mais profundos, em função da alta porosidade e de expressivos índices de vazios. Antunes e Salomão (2018) apontam uma boa permeabilidade para argissolos arenosos e latossolos, independentemente da textura, uma vez que apresentam poros intercomunicáveis e que favorecem a infiltração de água. Espera-se, para essa situação, coeficientes de permeabilidade entre $10^{-3}$ 
Tabela 4. Características geotécnicas das unidades geológico-geotécnicas.

\begin{tabular}{|c|c|c|c|c|c|c|c|c|c|c|}
\hline \multirow[t]{2}{*}{ Unidade } & \multirow{2}{*}{$\begin{array}{l}\text { Grau de } \\
\text { suscetibilidade } \\
\text { ao colapso }\end{array}$} & \multicolumn{4}{|c|}{ Classificações geotécnicas } & \multicolumn{2}{|c|}{$\begin{array}{l}\text { Compactação } \\
\text { (energia } \\
\text { normal) }\end{array}$} & \multicolumn{2}{|c|}{ N-SPT } & \multirow{2}{*}{$\begin{array}{l}\text { N.A. } \\
\begin{array}{c}\text { Prof } \\
(\mathrm{m})\end{array} \\
\end{array}$} \\
\hline & & Granulométrica & Textural & Unificada & Rodoviária & $\begin{array}{l}\gamma_{0} \text { máx. } \\
\left(\mathrm{g} / \mathrm{cm}^{3}\right)\end{array}$ & $\mathrm{h}_{\mathrm{ot}}(\%)$ & $\begin{array}{c}\text { Até } \\
3,0 \mathrm{~m}\end{array}$ & $\begin{array}{c}\text { Imp.I } \\
(\mathrm{m})\end{array}$ & \\
\hline 1 & $\begin{array}{c}9 \text { a } 12 \\
\text { (suscetível) }\end{array}$ & $\begin{array}{l}\text { - Argila arenosa } \\
\text { - Argila muito } \\
\text { arenosa } \\
\text { - Argila siltosa }\end{array}$ & $\begin{array}{l}\text { - Argilosa } \\
\text { - Média } \\
\text { argilosa }\end{array}$ & $\begin{array}{l}\mathrm{CL} \\
\mathrm{ML}\end{array}$ & $\begin{array}{c}\text { A4 } \\
\text { A5 } \\
\text { A6 } \\
\text { A7-5 }\end{array}$ & $\begin{array}{c}1,57 \mathrm{a} \\
1,80\end{array}$ & $\begin{array}{c}16,8 \mathrm{a} \\
24,5\end{array}$ & 2 a 6 & $\begin{array}{l}5,0 a \\
14,0\end{array}$ & $\begin{array}{l}\text { Seco } \\
a> \\
7,0\end{array}$ \\
\hline$\|$ & $\begin{array}{l}3 \text { a } 12 \text { (muito } \\
\text { pouco suscetível } \\
\text { a suscetível) }\end{array}$ & $\begin{array}{l}\text { - Argila siltosa } \\
\text { - Argila arenosa } \\
\text { - Silte arenoso } \\
\text { - Silte argiloso }\end{array}$ & $\begin{array}{l}\text { - Argilosa } \\
\text { - Muito } \\
\text { argilosa } \\
\text { - Média } \\
\text { argilosa }\end{array}$ & $\begin{array}{l}\mathrm{ML} \\
\mathrm{CH} \\
\mathrm{CL}\end{array}$ & $\begin{array}{l}\text { A7-5 } \\
\text { A7-6 } \\
\text { A6 }\end{array}$ & $\begin{array}{c}1,51 \mathrm{a} \\
1,81\end{array}$ & 8 a 25 & 3 a 8 & $\begin{array}{l}3,0 \mathrm{a} \\
15,0\end{array}$ & $\begin{array}{l}\text { Seco } \\
\text { ou > } \\
7,0\end{array}$ \\
\hline III & $\begin{array}{c}10 \text { a } 14 \\
\text { (suscetível } \\
\text { a altamente } \\
\text { suscetível) }\end{array}$ & $\begin{array}{l}\text { - Areia argilosa } \\
\text {-Argila arenosa }\end{array}$ & $\begin{array}{l}\text {-Média à } \\
\text { argilosa } \\
\text { - Média } \\
\text { argilosa } \\
\text {-Média } \\
\text { arenosa }\end{array}$ & $\begin{array}{l}S C \\
S M \\
C L\end{array}$ & $\begin{array}{l}\text { A6 } \\
\text { A2-4 } \\
\text { A4 }\end{array}$ & $\begin{array}{c}1,78 \mathrm{a} \\
2,05\end{array}$ & $\begin{array}{c}19,1 \mathrm{a} \\
9,7\end{array}$ & $\begin{array}{l}<2 \\
\text { a } 2\end{array}$ & $\begin{array}{c}10,0 \mathrm{a} \\
20,0\end{array}$ & $\begin{array}{l}\text { Seco } \\
\text { ou > } \\
18,0\end{array}$ \\
\hline IV & $\begin{array}{c}3 \text { a } 7 \text { (muito } \\
\text { pouco a pouco } \\
\text { suscetível) }\end{array}$ & $\begin{array}{c}\text { - Argila siltosa } \\
\text { com fragmentos } \\
\text { de rocha } \\
\text { - Silte argiloso }\end{array}$ & $\begin{array}{l}\text {-Média } \\
\text { argilosa } \\
\text { - Média } \\
\text { arenosa } \\
\text {-Argilosa }\end{array}$ & $\begin{array}{l}\mathrm{CH} \\
\mathrm{CL} \\
\mathrm{MH}\end{array}$ & $\begin{array}{l}\text { A7-5 } \\
\text { A7-6 } \\
\text { A6 }\end{array}$ & $\begin{array}{c}1,40 a \\
1,75\end{array}$ & $\begin{array}{c}37,0 \mathrm{a} \\
18,0\end{array}$ & $\begin{array}{c}19 a> \\
50\end{array}$ & $\begin{array}{c}1,0 \mathrm{a} \\
5,0\end{array}$ & $\begin{array}{l}\text { Seco } \\
\text { ou } 1,0 \\
\text { a } 4,0\end{array}$ \\
\hline V & $\begin{array}{l}2 \text { a } 5 \text { (muito } \\
\text { pouco a pouco } \\
\text { suscetível) }\end{array}$ & $\begin{array}{l}\text { - Silte argiloso } \\
\text { - Argila siltosa }\end{array}$ & $\begin{array}{l}\text { - Argilosa } \\
\text { - Muito } \\
\text { argilosa } \\
\text { - Média } \\
\text { argilosa }\end{array}$ & $\begin{array}{l}\mathrm{SM} \\
\mathrm{MH} \\
\mathrm{CL} \\
\mathrm{CH} \\
\mathrm{ML}\end{array}$ & $\begin{array}{l}\text { A2-6 } \\
\text { A7-5 } \\
\text { A7-6 }\end{array}$ & $\begin{array}{c}1,51 \mathrm{a} \\
1,63\end{array}$ & $\begin{array}{c}26,5 \mathrm{a} \\
23,3\end{array}$ & $\begin{array}{c}04 a> \\
50\end{array}$ & $\begin{array}{l}1,0 \mathrm{a} \\
10,0\end{array}$ & $\begin{array}{l}\text { Seco } \\
\text { ou } 2,0 \\
\text { a } 9,0\end{array}$ \\
\hline VI & $\begin{array}{l}4 \text { (muito pouco a } \\
\text { pouco suscetível) }\end{array}$ & $\begin{array}{l}\text { - Argila siltosa } \\
\text { - Outras }\end{array}$ & $\begin{array}{l}\text { - Muito } \\
\text { argilosa } \\
\text { - Outras }\end{array}$ & $\begin{array}{l}\mathrm{CH} \\
\mathrm{MH}\end{array}$ & A7-5 & 1,44 & 28,5 & $\begin{array}{c}03 a \\
07\end{array}$ & $\begin{array}{c}0,70 \mathrm{a} \\
3,10\end{array}$ & $\begin{array}{c}0,0 \mathrm{a} \\
2,0\end{array}$ \\
\hline VII & $\begin{array}{c}5 \text { a } 11 \text { (pouco } \\
\text { suscetível a } \\
\text { suscetível) }\end{array}$ & $\begin{array}{l}\text { - Argila arenosa } \\
\text { - Argila siltosa }\end{array}$ & - Argilosa & $\begin{array}{l}\mathrm{CL} \\
\mathrm{MH} \\
\mathrm{ML}\end{array}$ & $\begin{array}{c}\text { A6 } \\
\text { A7-5 }\end{array}$ & 1,61 & 24,8 & $\begin{array}{c}08 \mathrm{a}> \\
50\end{array}$ & $\begin{array}{c}2,0 a \\
5,0\end{array}$ & $\begin{array}{l}\text { Seco } \\
\text { ou } 1,5 \\
\text { a } 3,0\end{array}$ \\
\hline VIII & $\begin{array}{c}3 \text { a } 7 \text { (muito } \\
\text { pouco a pouco } \\
\text { suscetível) }\end{array}$ & $\begin{array}{l}\text { - Silte argiloso } \\
\text { - Argila siltosa } \\
\text { com presença de } \\
\text { fragmentos }\end{array}$ & $\begin{array}{l}\text { - Média } \\
\text { argilosa } \\
\text { - Argilosa } \\
\text { - Média } \\
\text { arenosa }\end{array}$ & $\begin{array}{l}\mathrm{CL} \\
\mathrm{CH} \\
\mathrm{MH}\end{array}$ & $\begin{array}{l}\text { A7-5 } \\
\text { A7-6 } \\
\text { A6 }\end{array}$ & $\begin{array}{c}1,40 a \\
1,80\end{array}$ & $\begin{array}{c}32,5 \mathrm{a} \\
17,5\end{array}$ & $\begin{array}{l}20 a \\
>50\end{array}$ & $\begin{array}{c}2,0 a \\
4,0\end{array}$ & Seco \\
\hline $\begin{array}{l}\text { Classific } \\
\text { - Muito } \\
\text { - Pouco } \\
\text { - Susce }\end{array}$ & $\begin{array}{l}\text { ção dos graus de s } \\
\text { ouco suscetível (0 a } \\
\text { suscetível (5 a 8); } \\
\text { vel (9 a 12); } \\
\text { te suscetível (13 a }\end{array}$ & $\begin{array}{l}\text { uscetibilidade ac } \\
\text { a 4); } \\
\text { 18). }\end{array}$ & meno 0 & apsivi & de solo & & & & & \\
\hline
\end{tabular}

e $10^{-5} \mathrm{~cm} / \mathrm{s}$. Por se situarem em áreas de baixa declividade, apresentam baixa potencialidade à erosão superficial. São solos não saturados, bons indicadores de materiais de empréstimo e que apresentam baixa erodibilidade, boa capacidade de suporte, expansibilidade nula e baixa compressibilidade.
Não obstante, o fato de essas coberturas denotarem maior suscetibilidade ao fenômeno da colapsividade de solos, outras unidades geológico-geotécnicas não devem ser negligenciadas, especialmente as unidades geológico-geotécnicas I e II, que se apresentam, muitas vezes, 


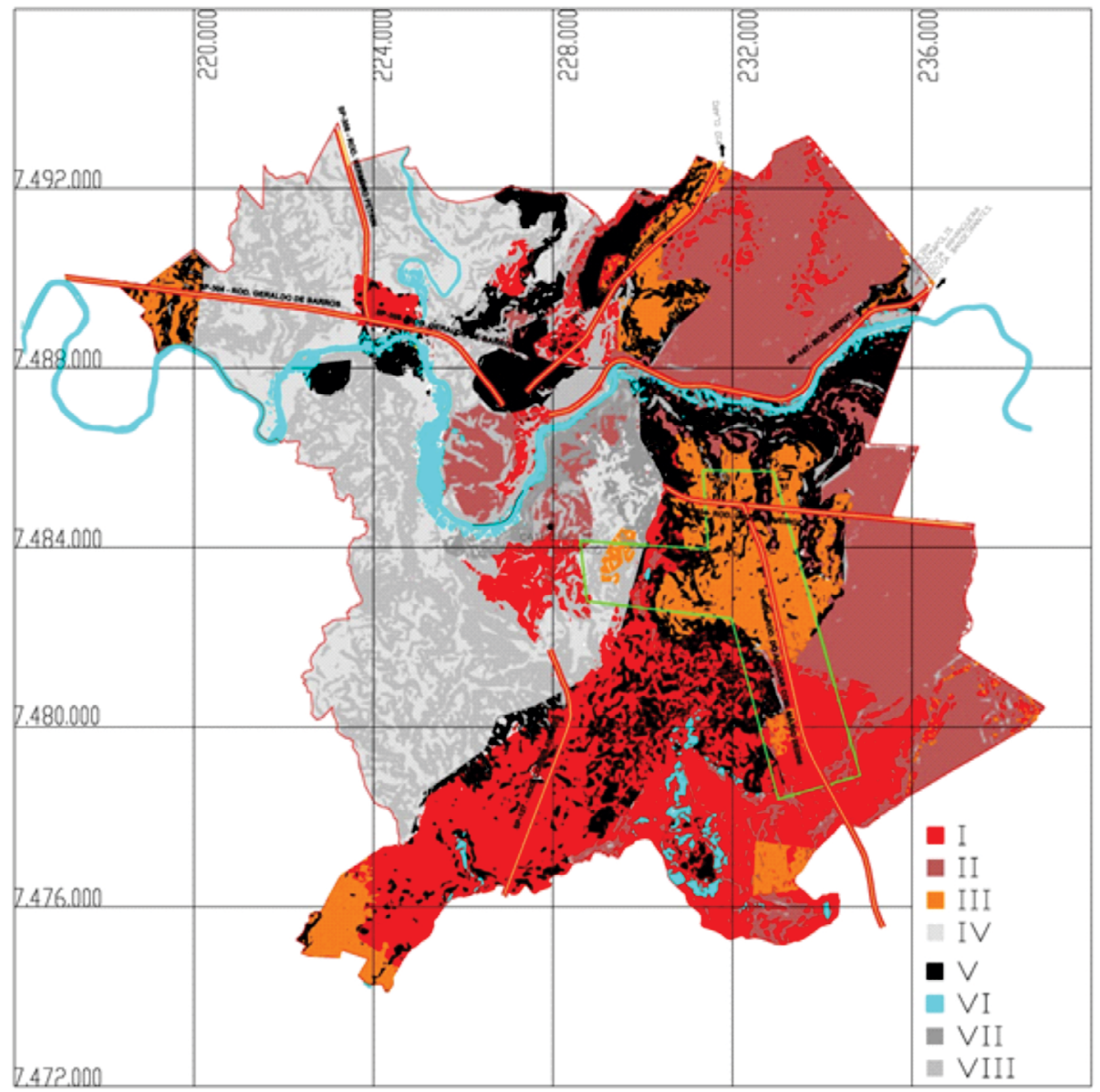

\begin{tabular}{|l|l|l}
\hline $\begin{array}{l}\text { UNIDADE } \\
\text { GEOLÓGICO- } \\
\text {-GEOTÉCNICA }\end{array}$ & $\begin{array}{l}\text { GRAU DE } \\
\text { SUSCETILILIDADE } \\
\text { AO COLAPSO }\end{array}$ & DESCRIÇÃO \\
\hline I & Suscetível & $\begin{array}{l}\text { Latossolos e nitossolos vermelhos desenvolvidos sobre a Fm. Tatuí, a } \\
\text { Fm. Irati e a Fm. Corumbataí. Ocorrem em declividades de 0 a 8\%. São } \\
\text { solos arailoarenosos/siltosos. }\end{array}$ \\
\hline II & $\begin{array}{l}\text { Muito pouco } \\
\text { suscetível a } \\
\text { suscetível }\end{array}$ & $\begin{array}{l}\text { Latossolos e nitossolos vermelhos desenvolvidos sobre a Fm. Serra } \\
\text { Geral. Ocorrem em declividades de 0 a 20\%. São solos argilo- } \\
\text {-siltosos/arenosos. }\end{array}$ \\
\hline III & $\begin{array}{l}\text { Suscetível a } \\
\text { altamente } \\
\text { suscetível }\end{array}$ & $\begin{array}{l}\text { Latossolos e argissolos vermelho-amarelos desenvolvidos sobre a Fm. } \\
\text { Pirambóia e principalmente sobre as coberturas cenozoicas correlatas } \\
\text { à Fm. Rio Claro. Ocorrem em declividades de 0 a 8\% a partir da cota } \\
580 \text { m. São solos aeralmente arenoarailosos. }\end{array}$ \\
\hline IV & $\begin{array}{l}\text { Muito pouco a } \\
\text { pouco suscetível }\end{array}$ & $\begin{array}{l}\text { Cambissolos háplicos e neossolos litólicos/regolíticos desenvolvidos } \\
\text { sobre a Fm. Tatuí, a Fm. Irati e a Fm. Corumbataí. Ocorrem em } \\
\text { declividades entre 0 e 8\%. São solos argilo-siltosos com fragmentos } \\
\text { rochosos. }\end{array}$ \\
\hline V & $\begin{array}{l}\text { Muito pouco a } \\
\text { pouco suscetível }\end{array}$ & $\begin{array}{l}\text { Argissolos em geral e nitossolos háplicos desenvolvidos sobre a Fm. } \\
\text { Tatuí, a Fm. Irati e a Fm. Corumbataí. Ocorrem em declividades de 0 a } \\
20 \% \text {. São solos predominantemente arailo-siltosos. }\end{array}$ \\
\hline VI & $\begin{array}{l}\text { Muito pouco a } \\
\text { pouco suscetível }\end{array}$ & $\begin{array}{l}\text { Gleissolos e neossolos flúvicos que ocorrem em regiões de várzea. } \\
\text { São solos argilosos/arenosos. }\end{array}$ \\
\hline VII & $\begin{array}{l}\text { Pouco suscetível a } \\
\text { suscetível }\end{array}$ & $\begin{array}{l}\text { Cambissolos háplicos e neossolos litólicos/regoliticos desenvolvidos } \\
\text { sobre a Fm. Serra Geral. Ocorrem em declividade de 3 a 20\%. São } \\
\text { solos argiloarenosos/siltosos. }\end{array}$ \\
\hline VIII & $\begin{array}{l}\text { Muito pouco a } \\
\text { pouco suscetível }\end{array}$ & $\begin{array}{l}\text { Cambissolos háplicos e neossolos litólicos/regolíticos desenvolvidos } \\
\text { sobre as formações Tatuí, Irati e Corumbataí. Ocorrem em declividade } \\
\text { superior a 8\%. São solos arailo-siltosos com fraamentos rochosos. }\end{array}$ \\
\hline
\end{tabular}

Figura 2. Carta geotécnica regional de solos colapsíveis, em escala 1:50.000, produzida na primeira etapa dos estudos, com indicação das unidades geológico-geotécnicas, indicando a zona-alvo (em verde). 
suscetíveis ao colapso. São solos lateríticos muito frequentes na área de estudo.

Após a elaboração da carta geotécnica aplicada a solos colapsíveis na etapa geral de mapeamento, foi escolhida uma área-alvo contemplando aquelas unidades que apresentaram maiores graus de suscetibilidade à colapsividade, em função dos critérios propostos. A área-alvo situa-se na porção sudeste da área (indicada em verde na Figura 2).

Os resultados obtidos nos ensaios edométricos de amostras indeformadas coletadas na etapa de semidetalhe mostram-se bastante compatíveis com as expectativas (Tabela 5 e Figura 3), haja vista que a determinação dos graus de suscetibilidade ao colapso apontados ainda na etapa geral, já indicava os solos da unidade III como suscetíveis a altamente suscetíveis ao fenômeno colapsível dos solos.

A geração das unidades geológico-geotécnicas estabelecidas nessa etapa de semidetalhe, na escala 1:25.000, ocorreu de acordo com as classes de suscetibilidade, cujos critérios e as principais características usadas são apresentados na Tabela 6. As classificações geotécnicas das unidades geológico-geotécnicas são mostradas na Tabela 7. As unidades geológico-geotécnicas correspondem às três classes de suscetibilidade ao colapso de solo, a saber:

- Classe A: solos com grau de suscetibilidade ao colapso entre 10 e 14 (suscetível a altamente suscetível) e que, de acordo com os resultados dos ensaios edométricos, apresentam índices de colapsividade entre 18 e $22 \%$ (severos). Apresentam declividade de até $8 \%$, e estão localizados entre as cotas 575 e $620 \mathrm{~m}$, aproximadamente, e acima de $640 \mathrm{~m}$. Correspondem pedologicamente aos LVA e esporadicamente aos PVA originados de coberturas correlatas à Formação Rio Claro, que apresentam textura média argilosa e esporadicamente argilosa;

- Classe B: solos com grau de suscetibilidade ao colapso entre 9 e 12 (suscetível). Apresentam declividade de até $8 \%$ e estão localizados abaixo da cota 575 e entre 620 e

Tabela 5. Resultados edométricos de amostras indeformadas: etapa intermediária.

\begin{tabular}{|c|c|c|c|c|c|}
\hline Amostra & Estágio (Tensão) kPa & $\mathrm{Cv}\left(\mathrm{cm}^{2} / \mathrm{s}\right)$ & $\mathrm{CC}$ & IC (\%) & GS \\
\hline & 12,5 & 0,00289 & & & \\
\hline & 25 & 0,00116 & & & \\
\hline & 50 & 0,00221 & & & \\
\hline \multirow[t]{7}{*}{1} & 100 & 0,00243 & - & 18,06 & Severo \\
\hline & 200 & 0,00433 & & & \\
\hline & 200 + inundação & 0,00123 & & & \\
\hline & 400 & 0,00770 & & & \\
\hline & 12,5 & 0,01017 & & & \\
\hline & 25 & 0,00269 & & & \\
\hline & 50 & 0,00175 & & & \\
\hline \multirow[t]{7}{*}{2} & 100 & 0,01899 & 0,277 & 18,89 & Severo \\
\hline & 200 & 0,00941 & & & \\
\hline & 200 + inundação & 0,00240 & & & \\
\hline & 400 & 0,01065 & & & \\
\hline & 1 & 0,00053 & & & \\
\hline & 9 & 0,01029 & & & \\
\hline & 26 & 0,01398 & & & \\
\hline \multirow[t]{7}{*}{3} & 56 & 0,04576 & - & 24,31 & Severo \\
\hline & 101 & 0,01795 & & & \\
\hline & 200 & 0,01564 & & & \\
\hline & 440 & 0,04335 & & & \\
\hline & 12,5 & 0,00261 & & & \\
\hline & 25 & 0,02515 & & & \\
\hline & 50 & 0,00808 & & & \\
\hline \multirow[t]{4}{*}{4} & 100 & 0,01187 & - & 21,83 & Severo \\
\hline & 200 & 0,00916 & & & \\
\hline & 200 + inundação & 0,00440 & & & \\
\hline & 400 & 0,01395 & & & \\
\hline
\end{tabular}

CV: coeficiente de adensamento; CC: índice de compressão; IC: índice de colapsividade; GS: grau de suscetibilidade. 

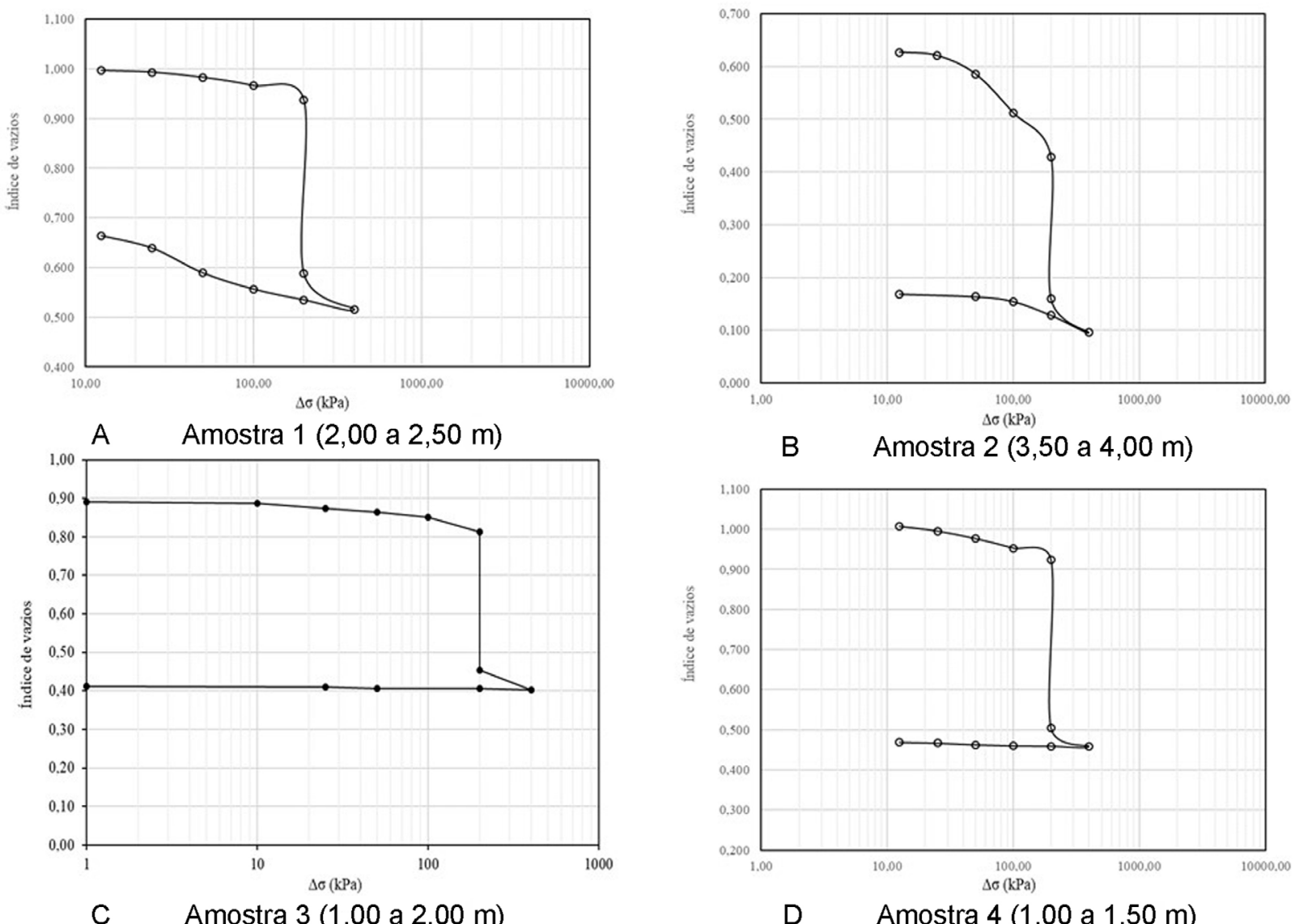

B $\quad$ Amostra $2(3,50$ a $4,00 \mathrm{~m})$

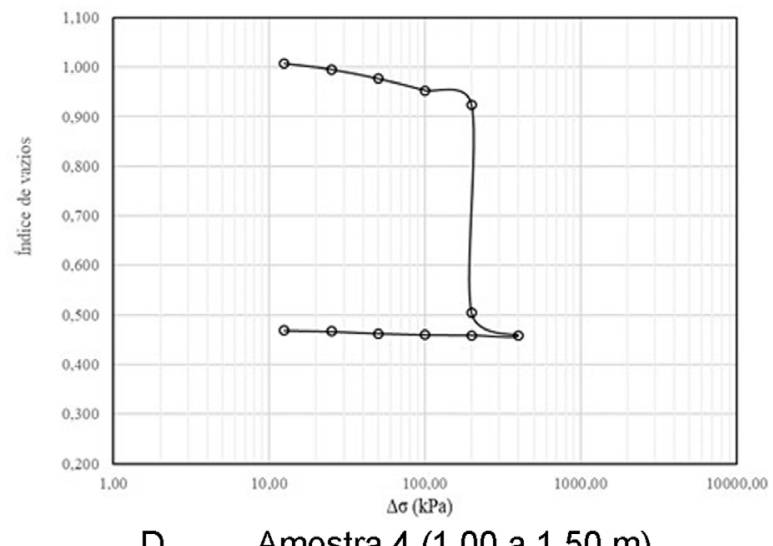

Figura 3. Curvas de adensamento.

Tabela 6. Critérios estabelecidos para a geração das unidades geológico-geotécnicas: classes de suscetibilidade ao colapso de solos da etapa intermediária.

\begin{tabular}{|c|c|c|c|c|c|c|}
\hline $\begin{array}{l}\text { Classe de } \\
\text { suscetibilidade } \\
\text { ao colapso do } \\
\text { solo }\end{array}$ & $\begin{array}{c}\text { Grau de } \\
\text { suscetibilidade }\end{array}$ & $\begin{array}{l}\text { Classe de } \\
\text { declividade }\end{array}$ & $\begin{array}{c}\text { Classe } \\
\text { hipsométrica }\end{array}$ & $\begin{array}{l}\text { Associação } \\
\text { pedológica/ } \\
\text { simbologia }\end{array}$ & $\begin{array}{l}\text { Litologia/ } \\
\text { unidades } \\
\text { litológicas }\end{array}$ & $\begin{array}{c}\text { Grau de } \\
\text { suscetibilidade } \\
\text { (baseado } \\
\text { em ensaios } \\
\text { edométricos) }\end{array}$ \\
\hline$A$ & $\begin{array}{c}10 \text { a } 14 \\
\text { (suscetível } \\
\text { a altamente } \\
\text { suscetível) }\end{array}$ & 0 a $8 \%$ & $\begin{array}{c}575 \text { a } 620 \\
\quad>640\end{array}$ & $\begin{array}{c}\text { Latossolo } \\
\text { vermelho- } \\
\text { amarelo (LVA) } \\
\text { Argissolo } \\
\text { vermelho- } \\
\text { amarelo (PVA) }\end{array}$ & $\begin{array}{c}\text { Coberturas } \\
\text { cenozoicas (Fm. } \\
\text { Rio Claro) }\end{array}$ & Severo \\
\hline B & $\begin{array}{c}9 \text { a } 12 \\
\text { (suscetível) }\end{array}$ & 0 a $8 \%$ & $\begin{array}{c}<575 \\
620 \text { a } 640\end{array}$ & $\begin{array}{c}\text { Latossolo } \\
\text { vermelho (LV) } \\
\text { Nitossolo } \\
\text { vermelho (NV) }\end{array}$ & \multirow{2}{*}{$\begin{array}{c}\text { Siltitos, argilitos, } \\
\text { folhelhos (Fm. } \\
\text { Irati e Fm. } \\
\text { Corumbataî); } \\
\text { diabásio (Fm. } \\
\text { Serra Geral); } \\
\text { coberturas } \\
\text { cenozoicas (Fm. } \\
\text { Rio Claro) }\end{array}$} & - \\
\hline C & $\begin{array}{c}2 \text { a } 8 \\
\text { (muito pouco } \\
\text { suscetível } \\
\text { a pouco } \\
\text { suscetível) }\end{array}$ & $>8 \%$ & Geral & $\begin{array}{c}\text { Argissolos } \\
\text { diversos (PV); } \\
\text { Cambissolos } \\
\text { (CX); } \\
\text { Nitossolos } \\
\text { litólicos (RL); e } \\
\text { outros }\end{array}$ & & - \\
\hline
\end{tabular}


Tabela 7. Classificações geotécnicas das unidades geológico-geotécnicas da etapa intermediária.

\begin{tabular}{|c|c|c|c|c|}
\hline \multirow{2}{*}{$\begin{array}{l}\text { Classe de suscetibilidade } \\
\text { ao colapso do solo }\end{array}$} & \multicolumn{4}{|c|}{ Classificações geotécnicas } \\
\hline & Granulométrica & Textural & Unificada & Rodoviária \\
\hline$A$ & $\begin{array}{l}\text { Areia argilosa } \\
\text { e areia arenosa }\end{array}$ & $\begin{array}{l}\text { Média argilosa e } \\
\text { argilosa }\end{array}$ & $\begin{array}{l}\mathrm{CL} \\
\mathrm{SM} \\
\mathrm{SC}\end{array}$ & $\begin{array}{c}\text { A2-4 } \\
\text { A4 } \\
\text { A6 }\end{array}$ \\
\hline B & \multirow[b]{2}{*}{$\begin{array}{c}\text { Argila siltosa; argila } \\
\text { arenosa; silte argiloso } \\
\text { e areia muito argilosa }\end{array}$} & $\begin{array}{l}\text { Argilosa e muito } \\
\text { argilosa }\end{array}$ & $\begin{array}{l}\mathrm{CL} \\
\mathrm{ML}\end{array}$ & $\begin{array}{l}\text { A6 } \\
\text { A4 }\end{array}$ \\
\hline C & & Idem B & $\begin{array}{l}\mathrm{CL} \\
\mathrm{ML} \\
\mathrm{MH} \\
\mathrm{CH}\end{array}$ & $\begin{array}{c}A 7-6 \\
A 7-5 \\
\text { A6 }\end{array}$ \\
\hline
\end{tabular}

$640 \mathrm{~m}$, aproximadamente. Correspondem pedologicamente aos latossolos vermelhos e esporadicamente aos nitossolos vermelhos de textura argilosa a muito argilosa, originados por coberturas argilosas correlatas às formações Irati, Corumbataí, Serra Geral e Rio Claro;

- Classe C: solos com grau de suscetibilidade ao colapso entre 2 e 8 (muito pouco suscetível a pouco suscetível). Apresentam declividade superior a $8 \%$. Correspondem pedologicamente aos argissolos diversos e aos solos pouco desenvolvidos, como cambissolos, neossolos litólicos e neossolos regolíticos, de textura argilosa a muito argilosa, originados litologicamente das formações Irati, Corumbataí e Serra Geral.

A carta geotécnica da área-alvo, na escala 1:25.000, é apresentada na Figura 4.

\section{DISCUSSÃo}

A metodologia do detalhamento progressivo, empregada neste trabalho, mostrou-se viável. Todavia, alguns aspectos importantes devem ser levados em consideração:

- Entre os vários critérios adotados para a avaliação do fenômeno da colapsividade de solos, pode-se afirmar que pelo menos três deles, embora não tenham interferido na avaliação da suscetibilidade do referido fenômeno, não atenderam às expectativas: Priklonskij (1952), Miheev (1962 apud Gibbs e Bara, 1967) e Ayadat e Hanna (2012). Souza Neto (2004) cita que os métodos de avaliação de solos colapsíveis baseados na granulometria e nas propriedades plásticas podem ser limitados, pois, para a realização de alguns ensaios de caracterização, destrói-se a estrutura deles, sobre a qual o comportamento colapsível é dependente. Por outro lado, o segundo e o terceiro critérios citados, geralmente, apontam no caminho inverso. Possivelmente, isso se deve ao fato de os autores terem desenvolvido esses critérios voltados para solos diferentes dos tropicais. Por outro lado, os critérios de Feda (1966); Andrei e Athanasiu (1979); Zuquette (1993); Lommler e Bandini (2015); e Vilar e Rodrigues (2015) se mostraram bastante coerentes e atenderam às expectativas, especialmente, nas fases mais regionais de mapeamento;

- Alguns cuidados requerem atenção pelos profissionais da área civil em empreendimentos desenvolvidos em solos suscetíveis ao fenômeno da colapsividade. Em terrenos planos, onde se apoiam fundações, estando o solo confinado, ocorrem deformações verticais acentuadas. Segundo Lollo (2012), as intervenções que visam reduzir os danos a edificações causados pelo processo colapsível podem ser de duas formas: mudança de projeto de fundação ou mudança construtiva. Assim, para o primeiro caso, o autor esclarece que elementos de fundação com maiores diâmetros, para estacas cravadas, reduzem a possibilidade de flambagem na cravação, enquanto para estacas in situ, o melhor é a adoção de menores diâmetros associados ao lançamento de brita ou concreto pouco plástico no fundo da escavação seguido de apiloamento. Já para minimizar os efeitos da infiltração de água em solos colapsíveis, o autor recomenda projetar um sistema adequado de drenagem de águas pluviais, impermeabilizar a área perimetral das construções com largura mínima de 1,5 m, instalar redes de água e esgoto no interior de dutos protetores, remover uma camada de solo superior que a necessária à implantação das redes, promovendo sua compactação, instalação de redes com utilização flexíveis e troca de tubulações antigas de fibrocimento ou cerâmica vermelha. Além disso, não devem ser negligenciados os cuidados relativos em obras de corte de taludes, pois ocorrendo a saturação desses solos em períodos chuvosos, a manifestação de escorregamentos poderá surgir, principalmente quando essas coberturas colapsíveis estão assentadas sobre solos mais impermeáveis, como é o caso da área de estudo; 


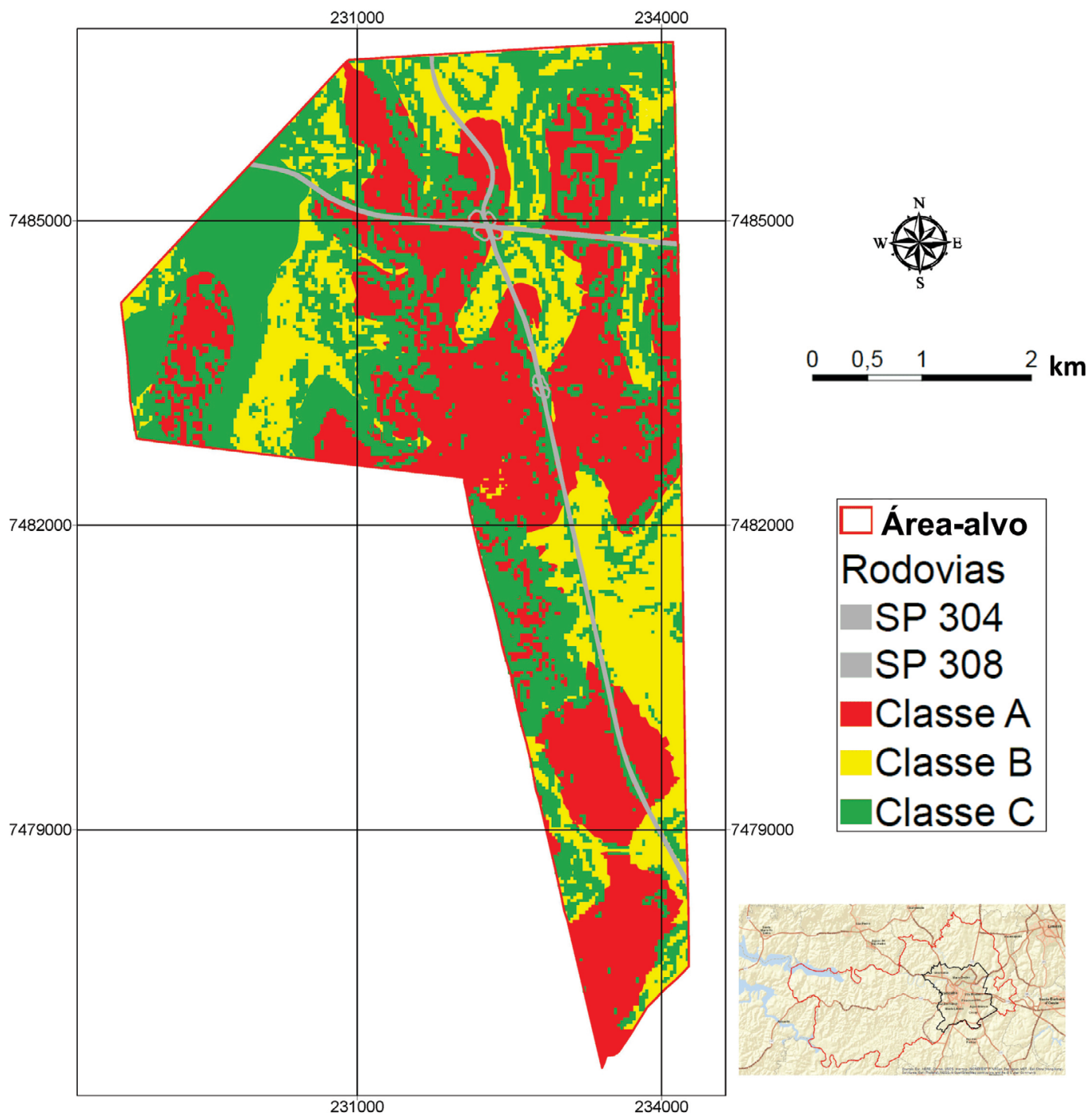

\begin{tabular}{|c|c|c|}
\hline $\begin{array}{l}\text { CLASSE DE } \\
\text { SUSCETIBILIDADE }\end{array}$ & $\begin{array}{l}\text { GRAU DE } \\
\text { SUSCETIBILIDADE } \\
\text { AO COLAPSO }\end{array}$ & DESCRIÇÃO \\
\hline A & $\begin{array}{l}\text { Suscetível a altamente } \\
\text { suscetível }\end{array}$ & $\begin{array}{l}\text { Latossolos vermelho-amarelos desenvolvidos sobre } \\
\text { as coberturas cenozoicas correlatas à Fm. Rio } \\
\text { Claro. Ocorrem em declividade de } 0 \text { a } 8 \% \text { em cotas } \\
\text { acima de } 575 \text { até } 620 \mathrm{~m} \text { e em cotas superiores a } \\
640 \quad \mathrm{~m} \text {. São solos predominantemente } \\
\text { arenoargilosos. }\end{array}$ \\
\hline B & Suscetível & $\begin{array}{l}\text { Latossolos e nitossolos vermelhos desenvolvidos } \\
\text { sobre as formações Irati e Corumbataí, sobre as } \\
\text { intrusões básicas da Fm. Serra Geral e sobre as } \\
\text { coberturas cenozoicas argilosas. Ocorrem em } \\
\text { declividade de } 0 \text { a } 8 \% \text { em cotas abaixo de } 575 \mathrm{~m} \text { e } \\
\text { acima de } 620 \text { até } 640 \mathrm{~m} \text {. São solos } \\
\text { predominantemente argiloarenosos/siltosos. }\end{array}$ \\
\hline C & $\begin{array}{l}\text { Muito pouco suscetível } \\
\text { a pouco suscetível }\end{array}$ & $\begin{array}{l}\text { Argissolos diversos, cambissolos háplicos, } \\
\text { neossolos litólicos/regoliticos e outros } \\
\text { desenvolvidos sobre as formações Irati e } \\
\text { Corumbataí e sobre as intrusões básicas da Fm. } \\
\text { Serra Geral. Ocorrem em declividade superior a } \\
\text { 8\%. São solos argilo-siltosos/arenosos. }\end{array}$ \\
\hline
\end{tabular}

Figura 4. Carta geotécnica da zona-alvo de solos colapsíveis, em escala 1:25.000, produzida na segunda etapa dos estudos, com indicação das unidades geológico-geotécnicas (classes de suscetibilidade ao colapso do solo). 
- De acordo com a metodologia de detalhamento progressivo utilizada neste trabalho, foi apontada apenas uma área-alvo, que contemplou unidades geológico-geotécnicas que apresentam solos com maiores potenciais para o desenvolvimento do fenômeno do colapso de solos. Entretanto, foi verificado que em outras unidades geológico-geotécnicas representadas por solos lateríticos, que apesar de apresentarem grau de suscetibilidade à colapsividade menor que o da área-alvo, não podem ser negligenciadas as possibilidades de ocorrência do fenômeno. Assim, sugere-se que para áreas urbanas de grande extensão, o estudo utilize setores da área urbana na primeira etapa do detalhamento progressivo (etapa geral) e duas ou mais áreas-alvo desses setores na etapa intermediária. Não obstante, deve-se considerar a prioridade de áreas dentro de um planejamento urbano sobre o assunto e a disponibilidade financeira para essas prioridades;

- A pesquisa buscou demonstrar a eficiência da metodologia do detalhamento progressivo, proposta por Cerri et al. (1996), quando aplicada nos estudos de avaliação ao fenômeno da colapsividade de solos em perímetros urbanos. Para tanto, fez-se uso da integração de informações geológicas, pedológicas, de declividade, hipsométricas e de dados de sondagens geotécnicas executadas na área com a análise de resultados de ensaios laboratoriais para a avaliação da suscetibilidade ao colapso de solos, procedimentos metodológicos esses que permitiram a geração de unidades geológico-geotécnicas, em diferentes escalas, das etapas geral e intermediária. Considerando-se que ensaios laboratoriais de caracterização de solos sejam de simples execução e pouco onerosos, esses foram realizados na etapa geral do detalhamento progressivo. Da mesma forma, os dados de sondagens geotécnicas realizadas na área de estudo, por terem sido disponibilizados sem custo pelas empresas de construção, também puderam ser utilizados nessa etapa. Já os ensaios edométricos, mais complexos e onerosos, foram executados na etapa intermediária do detalhamento progressivo.

\section{CONCLUSÕES}

A partir dos resultados, pode-se concluir que a metodologia do detalhamento progressivo se apresenta como uma ferramenta importante na elaboração de cartas de suscetibilidade ao fenômeno da colapsividade de solos em áreas urbanas, e pode ser aplicada para estudos de planejamento territorial por parte dos órgãos públicos e para a resolução de problemas de natureza geológico-geotécnica, especialmente aqueles pertinentes ao fenômeno da colapsividade, tendo como vantagem a otimização de recursos financeiros disponíveis, recursos pessoais e tempo.

As escalas utilizadas na etapa geral (1:50.000), para efeito de escolha de uma zona-alvo, e na etapa de semidetalhe (1:25.000), para efeito de detalhamento dessa zona-alvo, mostraram-se compatíveis com os objetivos deste trabalho.

Os ensaios laboratoriais selecionados para avaliação da ocorrência de solos colapsíveis, conforme a escala de mapeamento, mostraram-se compatíveis, de acordo com critérios estabelecidos por vários autores. Três critérios de definição de solo colapsível não atenderam às expectativas: Priklonskij (1952); Miheev (1962 apud Gibbs e Bara, 1967); e Ayadat e Hanna (2012), podendo ser desconsiderados nos procedimentos metodológicos propostos.

A integração das análises dos resultados obtidos nos ensaios geotécnicos de caracterização, compactação e edométricos com atributos morfométricos, como a declividade e a hipsometria, geológicos e pedológicos, permitiu a definição das unidades geológico-geotécnicas com enfoque na suscetibilidade ao fenômeno da colapsividade de solos. Considera-se que a metodologia pode ser aplicada também nos estudos das fases preliminares de obras civis, especialmente em estudos de viabilidade técnico-econômica, modelo conceitual e estudos de impacto ambiental, recomendando que pesquisas futuras desenvolvam avaliações nesse sentido, considerando as especificidades de cada tipo de obra e suas respectivas fases.

\section{REFERÊNCIAS}

Andrei, S., Athanasiu, C. (1979). Test data systematization and stockage to predict the parameters describing the behaviour of unsaturated soils. VII European Conference on Soil Mechanics \& Foundation Engineering, 1, 91-94. Brighton: ECSMFE.

Antunes, F. S., Salomão, F. X. T. (2018). Solos em Pedologia. In: A. M. S. Oliveira, J. J. Monticeli (eds.), Geologia de Engenharia e Ambiental, v. 2, p. 72-85. São Paulo: ABGE

ASTM. (1996). D 2435: Standard Method for OneDimensional Consolidation Properties of Soils. West Conshohocken: ASTM International.

ASTM. (2003).D 5353: Standard Test Method for Measurement of Collapse Potential of soils. West Conshohocken: ASTM International.

Ayadat, T., Hanna, A. M. (2012). Assessement of Soil Collapse Prediction Methods. International Journal of Engineering, 25(1), 19-26. https://doi.org/10.5829/idosi.ije.2012.25.01b.03 
Ayadat, T., Hanna, A. M. (2013). Design of foundations built on a shallow depth 9less than $4 \mathrm{~m}$ ) of Egyptian macro-porous collapsible soils. Open Journal of Geology, 3(3), 209-215. https://doi.org/10.4236/ojg.2013.33024

Basma, A. A., Tuncer, E. R. (1992). Evaluation and Control of Collapsible Soils. Journal of Geotechnical Engineering, 118(10), 1491-1504. https://doi.org/10.1061/ (ASCE)0733-9410(1992)118:10(1491)

Cerri, L. E. S., Akiossi, A., Augusto Filho, O., Zaine, J. E. (1996). Cartas e mapas geotécnicos de áreas urbanas: reflexões sobre as escalas de trabalho e proposta de elaboração com o emprego do método de detalhamento progressivo. VIII Congresso Brasileiro de Geologia de Engenharia, 2, 537548. Rio de Janeiro: ABGE.

Clemence, S. P., Finbarr, A. O. (1981). Design considerations for collapsible soils. Journal of the Geotechnical Engineering Division, 107(3), 305-317.

El May, M., Dlala, M., Chenini, J. (2010). Urban geological mapping: Geotechnical data analysis for rational development planning. Engineering Geology, 116(1-2), 129-138. https:// doi.org/10.1016/j.enggeo.2010.08.002

Ercoli, L., Zimbardo, M., Nocilla, N., Nocilla, A., Ponzoni, E. (2015). Evaluation of cliff recession in the Valle dei Templi in Agrigento (Sicília). Engineering Geology, 192, 129-138. https://doi.org/10.1016/j.enggeo.2015.04.008

Feda, J. (1966). Structural stability of subsident loess soil from Praha-Dejvice. Engineering Geology, 1(3), 201-219. https://doi.org/10.1016/0013-7952(66)90032-9

Gaaver, K. E. (2012). Geotechnical properties of Egyptian collapsible soils. Alexandria Engineering Journal, 51(3), 205-210. https://doi.org/10.1016/j.aej.2012.05.002

Gibbs, H. J., Bara, J. P. (1967). Stability problems of collapsing soils. Journal of the Soil Mechanics and Foundations Division, 93(4), 577-594. https://doi.org/10.1061/JSFEAQ.0001007

Jennings, J. E., Knight, K. (1957). The additional settlement of foundations due to collapse of structure of sandy sub soils on wetting. IV International Conference on Soil Mechanics and Foundation Engineering, 1, 316-319. Londres.

Lollo, J. A. (2012). Revisão dos métodos de Cartografia geotécnica de materiais geológicos colapsíveis. Revista Brasileira de Geologia de Engenharia e Ambiental, 2(1), 99-115. Disponível em: https://www.abge.org.br/downloads/ revistas/revisao.pdf. Acesso em: 18 maio 2021.
Lommler, J. C., Bandini, P. (2015). Characterization of collapsible soils. International Foundations Congress \& Equipment Exposition, 1834-1841. Saint Antonio: ASCE. https://doi.org/10.1061/9780784479087.167

Nakazawa, V. A., Prandini, L. F., Diniz, N. C. (1995). Subsidências e colapsos de solo em áreas urbanas. In: O. Y. Bitar (Coord.), Curso de geologia aplicada ao meio ambiente, p. 101-133. São Paulo: ABGE-DIGEO.

Olyansky, Y. I., Kuzmenko, I. Y., Shchekochikhina, E. V. (2016). Features of Construction Buildings on the Loessial Soil of Central Moldova. Procedia Engineering, 150, 2208-2212. https://doi.org/10.1016/j. proeng.2016.07.265

Pinto, C. S. (2002). Curso básico de mecânica dos solos. 2. ed. São Paulo: Oficina de Textos.

Popescu, M. E. (1986). A comparison between the behavior of swelling and collapsing soils. Engineering Geology, 23(2), 145-163. https://doi.org/10.1016/0013-7952(86)90036-0

Price, G. V. (1981). Methods of engineering geological mapping and their application on a regional scale in South Africa. Tese (Doutorado). Pretoria: University of Pretoria.

Priklonskij, V. A. (1952). Gruuntovedenie: vtoraira chast. Moscou: Gogeolizdot.

Rodrigues, R. A., Lollo, J. A. (2008). Características dos solos colapsíveis. In: J. A. Lollo (org.). Solos colapsiveis: identificação, comportamento, impactos, riscos e soluções tecnológicas, p. 59-72. São Paulo: Cultura Acadêmica.

Santos, A. R. (2017). Geologia de engenharia: o que é, como trabalha e suas relações com a engenharia geotécnica. Disponível em: http://www.ambientelegal.com.br/uma-aulasobre-geologia-de-engenharia-e-engenharia-geotecnica/. Acesso em: 10 set. 2017.

Souza Neto, J. B. (2004). Comportamento de um solo colapsivel avaliado a partir de ensaios de laboratório e campo e previsão de recalques devidos a inundação (colapso). Tese (Doutorado). Rio de Janeiro: Instituto Alberto Luiz Coimbra de Pós-Graduação e Pesquisa de Engenharia - UFRJ.

Teixeira, C. Z. (1993). Comportamento de estacas escavadas em solos colapsiveis. Dissertação (Mestrado). São Carlos: Escola de Engenharia de São Carlos - USP. https://doi. org/10.11606/D.18.1993.tde-26082014-164105 
Vilar, O. M., Rodrigues, R. A. (2015). Classical Methods to Identify Collapsible Soils. Soils and Rocks, 38(3), 265278. Disponível em: http://hdl.handle.net/11449/158814. Acesso em: 7 abr. 2021.

Zaine, J. E. (2000). Mapeamento geológico-geotécnico por meio do método do detalhamento progressivo: ensaio de aplicação na área urbana do município de Rio Claro. Tese (Doutorado). Rio Claro: Instituto de Geociências e
Ciências Exatas - UNESP. Disponível em: http://hdl.handle. net/11449/102900. Acesso em: 7 abr. 2021.

Zuquette, L. V. (1993). Importância do mapeamento geotécnico no uso e ocupação do meio físico: fundamentos e guia para elaboração. Tese (Livre-Docência). São Carlos: Escola de Engenharia de São Carlos - USP. https://doi. org/10.11606/T.18.2019.tde-27092019-143236 